\title{
Microwave Processing of Cement and Concrete Materials - Towards an Industrial Reality?
}

Adam Buttress*, Aled Jones* and Sam Kingman*

*National Centre for Industrial Microwave Processing (NCIMP),

Energy and Sustainability Division

The University of Nottingham,

University Park,

Nottingham,

$N G 72 R D$

adam.buttress@nottingham.ac.uk

ABSTRACT: Each year a substantial body of literature is published on the use of microwaves to process cement and concrete materials. Yet to date, very few if any have lead the realisation of a commercial scale industrial system and is the context under which this review has been undertaken. The state-of the-art is evaluated for opportunities, and the key barriers to the development of new microwave-based processing techniques to enhance production, processing and recycling of cement and concrete materials. Applications reviewed include pyro-processing of cement clinker; accelerated curing, non-destructive testing and evaluation (NDT\&E), and end-of-life processing including radionuclide decontamination.

KEYWORDS: Microwave Processing, Clinker, Cement; Hydration; Radioactive Waste. 


\subsection{Introduction}

Recognising that current trends in energy consumption cannot be sustained, G8 leaders in 2008 requested the International Energy Agency (IEA) to lead the development of a series of technology roadmaps. The purpose of which was to help identify the steps required to accelerate the adoption of radical new technologies that can realise ambitious worldwide carbon emission reduction targets over the medium to long-term. These focussed on the most critical low-carbon technologies affecting both energy supply and demand. Working with the World Business Council for Sustainable Development (WBSCD), the EIA published their Cement Technology Roadmap in 2009 [1]. This set out a possible route for the cement industry to make contributions to halving global $\mathrm{CO}_{2}$ emissions by 2050 . Increasing world demand for cement based materials, coupled with the pressing need to develop their more efficient and sustainable use will ultimately promote the adoption of new technologies that improve material resource efficiency within the life-cycle of cement and concrete materials.

One of the key drivers for the commercial utilisation of new technologies and processes is that they ultimately offer a techno-economic advantage in a competitive market. Microwave-based technologies offer a unique capability of generating heating in a way which overcomes constraints associated with conventional heating methods. Microwave processing systems have consequently found use in a wide range of industrial applications. Early adopters of the technology came from the food and rubber production industries [2]. Microwave systems were incorporated into drying and vulcanisation (for rubber) processes. These were more energy efficient and were relatively straight forward to develop. As fundamental understanding of the technology has advanced, so it has subsequently found use in a wide range of applications including soil remediation, volatile organic compound treatment and recovery; waste sludge processing, and mineral ore comminution [3].

Each year thousands of papers are published concerning the use of microwaves for material processing. Yet to date, relatively few have led to the realisation of industrial scale systems. Why is 
this? This question is the critical framework under which this review has been undertaken - a pragmatic assessment of previous work for its contribution to the development of commercial scale technologies, from the essential fundamental understanding to demonstration scale systems. What challenges remain and a critical analysis of the anticipated impact and hence commercial value of their adoption.

The full life-cycle of cement and concrete materials is considered. From pyro-processing for production of cement clinker, accelerated curing, non-destructive testing and evaluation to end-of-life recycling of demolition wastes and decontamination of concrete structures used in nuclear facilities.

\subsection{Background}

\subsection{Microwave Heating and Dielectric Properties}

Processes based on the use of microwave energy are attractive due to the unique way materials can interact with the microwave energy. Near-instantaneous, complete, phase-specific volumetric heating can be achieved [4] in addition to beneficial microwave specific effects, such as decreased sintering temperatures and improved physical and mechanical properties [2] [5] [6].

Materials which interact with microwave energy are called dielectrics. The extent of this interaction is dependent on it electronic structure of the material in question. The interaction of the dielectric with the microwave field induces an oscillation of the charge distribution in the material at the frequency of the applied field. Frictional forces develop and this energy is dissipated as heat. The two key elements that describe the behaviour of a dielectric material in a microwave field are the dielectric constant and loss factor. They are related by Eq.1:

Eq. $1 \varepsilon^{*}=\varepsilon^{\prime}-j \varepsilon^{\prime \prime}$

Where $\varepsilon^{*}$ is the complex relative permittivity (or complex dielectric constant); $\varepsilon^{\prime}$ is the relative permittivity (or dielectric constant); $\varepsilon$ "is the dielectric loss factor; $j$ is $\sqrt{ }-1$. 
The real part of the dielectric constant $(\varepsilon)$ represents the ability of a material to be polarised by an external electric field and is essentially a measure of the ability of charges and dipoles in a material to store energy. The imaginary part or dielectric loss factor is a measure of the material's ability to then convert this polarisation energy into heat.

Understanding dielectric properties are critical in all microwave systems to evaluate the response of the material to microwave energy and to ensure that the most efficient design is used to transfer the energy to the material. These can be determined at $2.45 \mathrm{GHZ}$ using the resonant cavity perturbation technique. This technique is often used because of the relative simplicity of its design, and the ability to measure solid and powdered samples at elevated temperature [7]; [8], [9]. Experimentally derived values for the dielectric constant and loss factor for concrete made from Type I Portland cement following curing for 4 weeks, tested under different conditions are shown in Table 1 [10]. The data is shown in comparison to water and a 0.3M Sodium Chloride solution. 
Table 1: Dielectric properties of concrete under differing test conditions [10].

Approximate

\begin{tabular}{ccc} 
Curing Conditions & $\begin{array}{c}\text { Dielectric Constant } \\
\left(\varepsilon^{\prime}\right)\end{array}$ & $\begin{array}{c}\text { Dielectric Loss } \\
\left(\varepsilon^{\prime \prime}\right)\end{array}$ \\
\hline Wet & 12.1 & 1.3 \\
Saturated & 6.0 & 0.5 \\
Air dried & 4.5 & 0.05 \\
Oven Dried & 4.0 & $<0.05$ \\
Water & 77 & 13 \\
0.3M NaCl & 70 & 17
\end{tabular}

The dielectric loss and loss tangent of water are significantly higher when compared to the concrete samples, with the salt solution higher still. The results indicate that the magnitude of the heating effect within the cement matrix would be determined by the distribution of free water. The aggregate phase and hardened cement paste are relatively poor heaters in comparison of free water held in the pore solution. The pore solution is also considered to be ionic in nature due to the dissolution of the cement clinker phases. From Table 1, it can be seen that the dielectric loss of the $0.3 \mathrm{M}$ salt solution is much higher than that of water. This is because the ionic content of the solution gives rise to additional loss mechanisms that cause a greater heating effect in the applied field. As such, from a view of microwave heating, cement and concrete materials can be considered a three phase system, comprising relatively transparent aggregate, hardened cement paste - containing bound water and hydroxyl groups, and the key absorbent phase, the ionic pore solution. As will be described later in the paper, the interaction of the pore solution with the applied microwave energy underpins many of the remote sensing technologies for microstructural analysis and hydration monitoring, as well as the breakage mechanisms in concrete delamination and benefaction in recycling. The dielectric properties can also be used to describe the mechanism by which clinker can be produced. 


\subsection{Applications of Microwave Processing to cement and concrete}

\subsection{Production of Cement Clinker}

The construction sector (including the manufacture of building materials) is worldwide the third-largest $\mathrm{CO}_{2}$ emitting industrial sector. It represents $10 \%$ of all $\mathrm{CO}_{2}$ emissions derived from human activity [11]. The vast majority of these emissions come from the provision of cement $(85 \%)$, of which $95 \%$ is released during its manufacture [12]; [13]. Table 2 shows the thermal energies associated with different building materials. While compared to metals and glass, the embodied energy of cement is relatively low it is often used in significantly higher quantities, particularly for heavy civil engineering projects such as roads, airports, dams and tunnels.

Table 2: Embodied energy in basic building materials [14]

\begin{tabular}{cc}
\hline Type of Material & Thermal Energy (MJ/kg) \\
\hline Cement & 5.85 \\
Lime & 5.63 \\
LP Cement & 2.33 \\
Steel & 42.0 \\
Aluminium & 236.8 \\
Glass & 25.8 \\
\hline
\end{tabular}

Despite the embodied energy of cement being less than that of metals, when it is used to produce concrete it forms the second most consumed material in the world after water. In 2006, 30 billion tonnes concrete was consumed globally [15]. The net heat balance for the manufacture of Ordinary 
Portland Cement (OPC) has been calculated theoretically as $1674-1799 \mathrm{~kJ} / \mathrm{kg}$ ([16], [17], [18]). The actual value is much higher in reality $(3100-3600 \mathrm{~kJ} / \mathrm{kg})$, if one was to account for the heat losses due to exhaust gasses and cooling processes. The clinkerisation of the raw meal during pyro-processing is considered one of the most energy intensive steps, accounting for approximately $60 \%$ of the total energy required [18]. Any reduction in residence time within the sintering furnace and the required sintering temperature would realise significant process benefits in terms of reduced production cost; embodied energy; and carbon emissions. However, it should be noted that alite is the major abundant phase in cement clinker. This impure form of $\mathrm{C}_{3} \mathrm{~S}$ forms a range of polymorphs between room temperature and $1100^{\circ} \mathrm{C}$, has a 'lower limit of stability' around $1250^{\circ} \mathrm{C}$, [13] so this temperature could be considered the minimum process temperature for clinker production, irrespective of the method used for manufacture.

A limited amount of work has been undertaken on the use of microwave energy for the clinkerisation of cement raw meal. The earliest and most effective work was undertaken in the 1980's. Quéméneur et al 1983, [19] undertook microwave-based clinkering of cement raw meal using a grooved resonant applicator $(0-3 \mathrm{~kW}, 2.45 \mathrm{GHz})$. A comparative analysis was undertaken by producing Portland cement by microwave processing and laboratory methods which were not described. By measuring the dielectric properties (absorbed power and dielectric loss) as a function of processing time, three distinct process domains were identified. These corresponded to dehydration and decarbonation of the raw materials; solid-state formation of the aluminoferrite $\left(\mathrm{C}_{4} \mathrm{AF}\right)$ and dicalcium silicate $\left(\mathrm{C}_{2} \mathrm{~S}\right)$ phase; and finally, the formation of a liquid phase, corresponding to the clinkering step and formation of $\mathrm{C}_{3} \mathrm{~S}$. The progress of the clinkering process was measured by determining the free lime content. After 7 minutes, no further reduction in free lime content was observed. This was assumed to indicate the completion of the clinkering process. XRD and SEM analysis showed that the clinker produced using the microwave process was of equivalent composition to that produced in the laboratory. Compressive strengths of micro specimens were also found to be comparable. 
Fang et al., [20] prepared Type 1 OPC and a range of coloured cements (white cement plus pigmenting materials) in a $900 \mathrm{~W}, 2.45 \mathrm{MHz}$ multimode cavity with a rotating turntable, essentially a domestic microwave oven. A single pellet method of sintering was adopted and compared to conventional firing using an electric furnace. The results showed that both OPC and white/coloured cement can be prepared by microwave processing. A microwave enhancing effect was observed, manifested by a reduction in free lime content; clinkering temperature (by $100^{\circ} \mathrm{C}$ ) and the preferential growth of $\mathrm{C}_{3} \mathrm{~S}$ in the microwave field. $\mathrm{Fe}_{2} \mathrm{O}_{3}$ in the raw meal was found to enhance the microwave process and was attributed to the reduction in clinkering temperature as it is a good absorber of microwave energy. In this case, the $\mathrm{Fe}_{2} \mathrm{O}_{3}$ acts a susceptor. This is a material that readily heats in the microwave field and can then dissipate the heat by conduction to the surrounding, less microwave absorbent phases. If the $\mathrm{Fe}_{2} \mathrm{O}_{3}$ is finely disseminated throughout the pellet, then more rapid and possibly more efficient heating occurs. It could effectively be considered a pseudo-volumetric method of heating, giving rise to the lower sintering temperature observed over the conventional firing process. While the researchers were able to demonstrate in principle that the technique could work, it is suspected that the process consumed relatively massive amounts of energy to produce a small pellet of material. This would negate any benefit from the reduction in clinkering temperature. The reliance on indirectly heating the clinkering mixture using susceptor could introduce processing constraints, based on the amount and its distribution within the composite raw meal.

The preparation of $\mathrm{C}_{3} \mathrm{~S}$ was also undertaken by Li et al., [21] who again found that microwave sintering occurred at a lower temperature $\left(100-150^{\circ} \mathrm{C}\right)$. Here this was attributed to an increase in ion diffusion, brought about by the interaction of ions with the electric field, the so called non-thermal microwave effect [17], although the true nature of this effect or indeed whether it exists at all, is still some matter of debate. They also noted that the ability of the raw mix to absorb microwave energy is highly temperature dependant. Quartz $\left(\mathrm{SiO}_{2}\right)$ was the most thermally inert component. Early work has shown that at elevated temperatures $\left(>110^{\circ} \mathrm{C}\right) \mathrm{SiO}_{2}$ gels were found to heat and melt quickly [22]. Although for pyro-processing of cement clinker, quartz contained in the raw meal is crystalline and microwave transparent, so this is irrelevant. 
The heating mechanism in these studies was reported to be solely from microwave energy. However, Ma et al., [23] stated that the coupling of the raw meal with microwave energy at low temperatures is not sufficient to induce volumetric heating. Alumina was considered by [19] to be a good absorber of microwave energy, but this was a relatively early paper. While at high temperatures it is able to couple to microwave energy to a greater degree, at room temperature it is regarded largely transparent. However, they had not considered that $\mathrm{Fe}_{2} \mathrm{O}_{3}$ is a good absorber of microwave energy, which in previous studies acted as a susceptor [20]. As such, they used a combined process, where the raw meal was first heated to a critical temperature $\left(1500^{\circ} \mathrm{C}\right)$; at which the microwave absorbability of the materials is optimised, and then transferred to a microwave cavity for sintering $(1000 \mathrm{~W}, 2.45 \mathrm{GHz}$, power density $45 \mathrm{kWm}^{-3}$ ). Compared to conventional sintering, XRD peaks of $\mathrm{C}_{3} \mathrm{~S}$ were found to be stronger in the combined process. The process was enhanced by the inclusion of a number of metal oxides $\left(\mathrm{MnO}_{2} ; \mathrm{CuO}\right.$; and $\left.\mathrm{Ni}_{2} \mathrm{O}_{3}\right)$, again as susceptor in the $\mathrm{CaO}-\mathrm{SiO}_{2}$ binary system. These coupled with the microwave field and induced rapid heating, further enhancing the rate of mineral formation.

Long et al., [24] found that heating sulfoaluminate cement with microwave energy alone (25 minutes, $700 \mathrm{~W}, 2.45 \mathrm{GHz}$, power density $30 \mathrm{kWm}^{-3}$ ) resulted in a clinker with residual $\mathrm{CaCO}_{3}$ content, indicating incomplete decomposition of the starting materials. They were able to achive a better result, evaluated by measuring the free-lime (f-CaO) content of the clinker products, by pre-heating to just below the calcination temperautre $\left(1000-1200^{\circ} \mathrm{C}\right)$ before microwaving the samples for a couple of minutes. For comparison, the same material was prepared using conventional heating for $1 \mathrm{~h}$ at $1300^{\circ} \mathrm{C}$. They also undertook a similar study using Portland cement clinker [25]. It was found that increasing the temperature prior to microwave processing, reduced the free lime content. Again the presence of $\mathrm{Fe}_{2} \mathrm{O}_{3}$ in the raw meal enhanced the clinkering effect.

The benefits of the microwave treatment remains to be seen in the work reporting a combined heating approach as it was necessary to conventionally pre-heat the raw meal components to temperatures close to that required for the calcination process. The reported benefit of a reduction in clinkering temperature using microwave treatment is therefore considered overstated. Given only the marginal 
savings in energy, or conversely slight increases in throughput that is inferred, the capital cost alone of an industrial system could never be justified.

This is further illustrated with the work of McGill et al., [26]. The heating rates of various pure materials; including some components of cement clinker raw meal, were investigated by using a variable power microwave applicator $(500-2000 \mathrm{~W}, 2.45 \mathrm{GHz})$. The maximum material temperature achieved at as function of power level is reproduced in Table 3. It can be seen from the table that $\mathrm{Fe}_{3} \mathrm{O}_{4}$ is the most effective dielectric material.

Table 3: Effect of microwave incident power on heating rates of cement raw meal components [26].

\begin{tabular}{|c|c|c|c|c|c|c|c|c|}
\hline \multirow{2}{*}{$\begin{array}{l}\text { Clinker } \\
\text { Phase }\end{array}$} & \multicolumn{2}{|c|}{$500 \mathrm{~W}$} & \multicolumn{2}{|c|}{$1000 \mathrm{~W}$} & \multicolumn{2}{|c|}{$1500 \mathrm{~W}$} & \multicolumn{2}{|c|}{$2000 \mathrm{~W}$} \\
\hline & Temp & Time & Temp & Time & Temp & Time & Temp & Time \\
\hline & ${ }^{\circ} \mathrm{C}$ & $\min$ & ${ }^{\circ} \mathrm{C}$ & $\min$ & ${ }^{\circ} \mathrm{C}$ & $\min$ & ${ }^{\circ} \mathrm{C}$ & $\min$ \\
\hline$\alpha-\mathrm{Al}_{2} \mathrm{O}_{3}$ & 385 & 7 & 463 & 7 & 498 & 7 & 547 & 7 \\
\hline $\mathrm{CaCO}_{3}$ & 32 & 7 & 42 & 7 & 51 & 7 & 65 & 7 \\
\hline $\mathrm{Fe}_{2} \mathrm{O}_{3}$ & 60 & 7 & 87 & 7 & 101 & 7 & 130 & 7 \\
\hline $\mathrm{Fe}_{3} \mathrm{O}_{4}$ & 1118 & 7 & 1144 & $3.5^{\star}$ & 1123 & $3^{\dagger}$ & 905 & $1^{\dagger}$ \\
\hline $\mathrm{SiO}_{2}$ & 33 & 7 & 44 & 7 & 55 & 7 & 73 & 7 \\
\hline
\end{tabular}

Note: * - temp passed thermocouple limitation, ${ }^{\dagger}$ - heating terminated due to sample arcing

Based on the data in Table 3, the processing energy demand for producing cement clinker using a microwave power level of 500W and 2000W are presented in Table 4. The composition of the clinker phase was based on a report by The British Geological Survey [27] and typical compositions of OPC cement clinker given by Taylor [28]. Assumptions made in the calculation are:

1. All the applied energy is absorbed by the sample; and 
2. The dielectric properties of the phase do not change with temperature, so the resulting temperature response of a particular phase was linear, enabling it to be scaled to give the energy required (in $\mathrm{kWh} / \mathrm{t}$ ) to achieve $1400^{\circ} \mathrm{C}$.

Table 4: Calculated energy demand for production of cement from raw meal components using microwaves

\begin{tabular}{cccc}
\hline & & \multicolumn{2}{c}{ kWh/t using $\mathbf{M W}$ for $\mathbf{1 4 0 0 ^ { \circ } \mathrm { C }}$} \\
Clinker Phase & \% Composition & \multicolumn{2}{c}{ Power (W) } \\
& 5 & $\mathbf{5 0 0}$ & $\mathbf{2 0 0 0}$ \\
\hline${\mathrm{a}-\mathrm{Al}_{2} \mathrm{O}_{3}}$ & 50 & 8167 & 98 \\
$\mathrm{CaCO}_{3}$ & 3 & 136 & 15372 \\
$\mathrm{Fe}_{2} \mathrm{O}_{3}$ & 3 & 7 & 243 \\
$\mathrm{Fe}_{3} \mathrm{O}_{4}$ & 10 & 990 & 9 \\
$\mathrm{SiO}_{2}$ & 9.3 & 1782 \\
$\mathrm{Total} \mathrm{Energy} \mathrm{Requirement} \mathrm{(GJ/t)}$ & & 17.5 \\
\hline
\end{tabular}

The calculated energy requirement to heat 1 tonne of raw meal to $1400^{\circ} \mathrm{C}$ was $9.3 \mathrm{GJ} / \mathrm{t}$ at $500 \mathrm{~W}$ and $17.5 \mathrm{GJ} / \mathrm{t}$ at $2000 \mathrm{~W}$. Comparing these values to an energy requirement using conventional pyroprocessing of 3.7GJ/t by the European Cement Research Academy [29], it can be seen that microwave based pyro-processing does not offer any advantage. In fact the energies needed are $250 \%$ and $470 \%$ higher. This is principally because the main raw meal phases: calcium carbonate; alumina and silica have dielectric properties that result in them being relatively poor heaters in an applied microwave field. Despite these being only approximate calculations based on a number of assumptions, it's highly unlikely that any techno-economic model for this application of microwaves would support the case for further development of the technology.

\subsection{Accelerated Curing}


The term "curing" is frequently used to describe the process by which hydraulic-cement concrete matures and develops hardened properties over time as a result of the continued hydration of the cement in the presence of adequate water and heat. Curing is defined by Holm and BirchRasmussen [29] as "action taken to maintain moisture and temperature conditions in a freshly placed cementitious mixture to allow hydraulic cement hydration and (if applicable) pozzolanic reactions to occur so that the potential properties of the material may develop". Taylor, [28] defined curing as 'storage under conditions such that hydration occurs', where hydration is the 'totality of the changes that occur when an anhydrous cement, or one of its constituent phases is mixed with water.

Curing of concrete be undertaken using steam, heating coils, or electrically heated pads. These methods require the use of expensive equipment and relatively long processing cycles of up to 24 hours [30]. For steam curing, the advantages are also offset by durability issues associated with the delayed formation of expansive minerals within the material [31-33]. In addition, the process can suffer from non-uniform hydration of the cement clinker, resulting from temperature gradients within the material due to inherent thermal insulation effects [34]. Providing the process is optimised for the material to be treated, microwave assisted curing of cement and concrete could yield benefits in terms of reductions in processing time; energy efficiencies and cost, in addition to increased material performance, particularly at early ages. Many patented concepts also exist using microwave energy to cure concrete [35-37].

Work was undertaken by Xuequan et al [38] on mortar prisms cured in a domestic-type microwave at two power levels. It was found that on low power microwave-induced curing, the increase in compressive strength over the short and long-term was reported. This indicates an increase in early strength gain, without any detrimental effect at later ages. Measurements of the permeability showed that the microwave treated specimens were denser than the controls, inferring a reduction in porosity and the action of plastic shrinkage. Microwave treatment at higher power levels led to further increases in short term strength, but at the cost of the strength measured at 28 days. 
Working with prisms made from OPC, Hutchison et al [39], cured them in a microwave field, the strength of which was crudely controlled by including a specific volume of water alongside the specimens. They found that microwave curing reduced the length of the induction period and increased the degree of hydration without affecting the long-term strength. The actual delivered power to the specimens was very low $50 \mathrm{~W}$, especially considering $1000 \mathrm{ml}$ of water was also placed in the cavity as an absorber. This would have prevented temperature rises within the specimens, above those of an optimum condition for accelerated curing, as reported by some other workers. But given no temperature measurements were reported, it is difficult for the authors to ascertain what benefits such a low dose of microwaves could have contributed, without the workers providing more details.

Donqxu and Xuequan [38] studied the use of microwave energy for dewatering concrete. By removing this excess water after the material has been set, densification of the concrete and a corresponding increase in both compressive and flexural strength can be achieved, in addition to a reduction in the amount of cement used and formwork required. It is difficult to envisage how this could be deployed commercially though. Applicator design is critical to a successful microwave process, as it delivers the microwave energy to the material in the correct way in order to be effective. A such, they are designed to treat material of a specific size and shape, irrespective of whether it is a batch or continuous process. The structure or workpiece to be dewatered could be a variety of shapes and sizes, so it is difficult to see how a 'one size fits all' applicator could be designed for dewatering, particularly since the system would need to be highly mobile. Confinement of the microwave field, both from a health and safety and electromagnetic compatibility perspective, would also be a significant challenge.

Leung and Pheeraphan [30] investigated accelerated curing of cement mortars and concrete specimens. It was found that, for all the mortar specimens, the seven day strengths were reduced compared to the control group. The concrete specimens had equivalent or marginally less strength compared to the controls. These results contrasted with the work of other researches using Type I Portland cement $[38,39]$. It was suggested by the authors that the higher heat evolution on hydration 
in the specimens, made from Type III Portland cement, adversely affected the ultimate strength of the test specimens by making them more sensitive to heating by the applied microwave field. Other authors (described later) have shown that excessive heating can lead to drying of the hydrating material, leading to damage to the microstructure resulting in lower strengths, compared to specimens dried by conventional methods. Optimisation of the process is clearly required, tailored to the material to be heated, both in terms of applied power and residence time within the cavity to avoid such outcomes. Indeed by optimising the curing regime, the same workers later reported that early strength gains could be achieved, without affecting long-term strength [40].

The effect of microwave curing on mortar specimens made from Type I OPC and blended mortars with Supplementary Cementitious Materials (SCMs) was investigated by Sohn and Johnson [41]. Again optimisation of the curing regime was required to maintain long-term strength development. This was aided by the use of an internal thermocouple to monitor and control the temperature of the material and was clearly beneficial for optimisation of the microwave curing process, although of course they should not be left in situ during treatment. As found by other workers, excessive temperature rises and moisture loss adversely affected long-term performance and durability. Benefits can only be realised in terms of accelerated curing, while maintaining long-term strength, providing adequate control of the process is achieved.

Topçu et al [42] undertook a similar study investigating the optimum microwave curing conditions of fly ash mortars. The work optimised the material composition and microwave curing parameters to obtain the best combination of accelerated curing and retention of long-term strength. Despite higher early-age strengths due to accelerated curing, long-term strengths were slightly less. They were able to correlate the early-age strength to the long-term strength with a fair degree of accuracy (ca. $\pm 2 \%$ ). Indicating that microwave curing could be used as a performance assessment tool as investigated by Tumidajski et al [43] and described later in this section.

The use of a microwave curing method in the production of Ultra High Performance Concrete (UHPC), incorporating so-called nanoscale pozzolans was reported by Korpa and Trettin [44]. While 
microwave curing resulted in higher strengths, the effect of the microwave curing was not differentiated from that of the nanoscale pozzolans. It was concluded that the microwave curing method caused an 'amplification' effect in material performance, over the UHPC material and nanoscale pozzolans alone.

Makul and Agrawal [34] recently published work showed that the use of a Cober Electronics industrial microwave generator $(2.45 \mathrm{GHz}, 6.0 \mathrm{~kW})$ into a multimode applicator, resulted in specimens that exhibited increased strength over those cured under autoclaved and lime saturated conditions, particularly at early ages. Microstructural and compositional analysis did reveal differences in the cement specimens based on the applied curing regieme. Ettringite (AFt) was found in the microwaved and autoclaved specimens, but not in those curing under lime saturated water, where lath and platelike crystals were identified. However, this would be expected since hydroxide ion concentration within the cement paste has a significant effect on the formation and morphology of ettringite [45]. The platelike phase identified by the authors could well have been precipitated calcium hydroxide or possibly monosulfate (AFm). Interestingly, it was reported that microwave curing promotes disorder within the C-S-H phase, which provides cement with its long-term mechanical strength [28]. This was evidenced using SEM and XRD analysis of the cement pastes. The samples cured for 28 days in lime-saturated water showed relatively large well formed CSH crystals. Those subject to microwave curing were smaller, fractured and more randomly orientated. Their XRD patterns showed the peaks of calcium silicate hydrate $\left(\mathrm{Ca}_{3} \mathrm{SiO}_{5}\right)$, calcium hydroxide $\left(\mathrm{Ca}(\mathrm{OH})_{2}\right)$, residual lime $(\mathrm{CaO})$, and Xenotile $\left(\mathrm{Ca}_{6}\left(\mathrm{SiO}_{3}\right)_{6}\left(\mathrm{H}_{2} \mathrm{O}\right)\right)$ to be poorly resolved, suggesting an uncertain and complicated shape, despite being crystalline. This disorder could then lead to micro-cracking and an associated loss in compressive strength as observed by other workers [46]. If this cannot solely be attributed to excessive material shrinkage resulting from rapid dewatering due to high temperature rises on microwave treatment. Rattanadecho et al [56] have so far been the only workers to demonstrate the scalability of microwave based accelerated curing using a continuous microwave thermal processor. The microwave power was generated using 14 compressed air-cooled magnetrons (800W each) generating a total power output of $11.2 \mathrm{~kW}$. The results of this work showed that microwave assisted curing accelerated the early strength of the specimens, without affecting their long-term strength. 
Interestingly, higher applied power reduced the strength down to equivalence (approximately $2.4 \mathrm{~kW}$ ). This was attributed to micro-cracking of the specimens induced by excessive dehydration as opposed to heat generation. The $\mathrm{w} / \mathrm{c}$ ratio also had an effect on the response of the material to microwave curing and its ultimate strength gain. Those specimens with the lowest $w / c$ ratio performed the best, corresponding to higher rates of heat liberation on hydration and increased coupling to the applied microwave energy. As a potential commercial system, the process reported cannot be scaled, at the frequencies reported, such that it can cure modular pre-cast concrete of the of the sizes used in industry, principally due to the penetration depth of the microwaves at $2.45 \mathrm{GHz}$. The specimens cured in the study were cubes with sides only $5 \mathrm{~cm}$ in length, so in this case the energy heats the specimens volumetrically. If the same system were used to cure much larger specimens, the energy would attenuate through the bulk, such that the heating effect would be confined to the near surface, leaving the middle largely cold. One of the principal advantages of microwave curing - volumetric heating would therefore not be achieved. Using energy of a lower frequency in the radio - frequency range can mitigate the problem, but this would require a complete system redesign in this case.

Tumidajski et al., [43] reported an interesting study correlating the 6 hour compressive strengths of batched ready-mix concrete subject to microwave curing, to standard wet-cured, 28 day strengths. This was with a view to using the 6 hour strengths as an early predictor for batch specific nonconformance, which is typically based on the strengths of test specimens cured for 3 or 7 days. The $R^{2}$ value was 0.98 indicating that microwave curing could be a fast and inexpensive quality control tool, allowing the rapid prediction of 28 day strengths from specimens cured for 6 hours. While only a limited number of specimens were tested in this work, a relatively immediate test for batch conformance on a construction site would be very useful. But its robustness would have to be proven with extensive testing on a vast array of cement compositions and not a trivial undertaking.

Bescher et al., [47] were able to determine the w/c ratio of freshly mixed calcium sulfoaluminates cement to a high degree of accuracy using a 900W domestic-type microwave oven. The authors reported that the $w / c$ ratio could be determined to an accuracy of $w / c \pm 0.05$. However, to prevent hydration of this type of rapid-setting cement, citric acid was added to the mixture. This would seem to 
limit the usefulness of the technique. The set-retarder would have to be added immediately on mixing, the use of which may not be practical or desirable during batch mixing in on-site conditions.

\subsubsection{Summary}

It has been demonstrated that microwave based techniques can be used successfully to accelerate the curing process. The work reviewed was generally conducted at laboratory scale on relatively small specimens, with only one pilot-scale system reported. This being designed to investigate continuous processing, rather than accelerated curing of specimens much larger than those used in the laboratory-based studies.

To avoid adversely affect the long-term strength of the specimens subject to microwave curing, the curing regime used had to be carefully controlled, so as not to cause drying of the cement paste. On initial mixing this could cause dehydration of the primitive hydrating phases, or at later ages rapid dewatering resulting in excessive volumetric shrinkage. Both conditions causing a loss of long-term mechanical strength, but in the work reported, this was generally only measured up to 28 days age. In addition, it was reported by some researchers that microwave curing promotes disorder within the $\mathrm{CSH}$ phase, not seen in equivalent specimens cured conventionally. This too is likely to result in a loss of mechanical strength and certainly warrants further investigation.

The use of microwave curing of early-age specimens for the prediction of long-term strength, as well as the determination of $\mathrm{w} / \mathrm{c}$ ratio in freshly mixed cement paste was also investigated. Both were relatively successful.

\subsection{Non-destructive Testing and Evaluation, Cure-State Monitoring and} Microstructural Investigation 
Once concrete has been cast, either as structural or pre-cast moulds, the determination of its properties becomes very difficult without actually damaging it in the process. Testing methods that involve load testing can damage the sample are not ideal, and may also require coring of larger structures to produce a test specimen. The development of any commercial device that can characterise the properties of hardened cement mortar or concrete, without actually damaging it would be extremely valuable. If one was to consider strength testing, after initial mixing, the cement paste forms a thixotropic gel, which then undergoes a series of morphological and compositional changes as hydration progresses to produce a hardened material [48]. While the concrete can be demoulded, it is unlikely to have achieved sufficient strength for its intended application, as the transition from one cure-state to another is gradual. Any kind of remote method of sensing the change from one cure state to another would again be very valuable as an on-site diagnostic tool.

A very large body of work has been published concerning the use of microwave energy to probe the chemical and microstructural composition of cement and concrete. Non-destructive testing and evaluation methods for water content determination in building materials, based on the application of microwave energy, have been subject to research for several decades [49] [50] [51]. This type of materials testing can be grouped according the physical basis of the measurement technique: reflection (such as open ended coaxial probe/waveguide method and the 'infinite' sample method); transmission and resonance systems [48].

Some early work was carried out by Gorur et al [52]. They proposed a method for monitoring the hydration kinetics and therefore degree of hydration within small cement paste samples. This was based on the fact that the dielectric properties of the hydrating cement paste can be correlated with its free-water content, if the material is in a sealed condition - as only hydration reactions can consume water. The experimental work was undertaken using OPC at different $w / c$ ratios and using different admixtures. It was shown that the rate of hydration could be followed using the change in the complex dielectric constant, as a function of hydration time. Differences in the rate of reaction could be differentiated due to the effects of the three admixtures. 
Using the infinite sample method, Moukwa et al [53] were able to correlate changes in the slope of the relative permittivity with different phases of the hydration process, as described by Mindess and Young [54], typically followed using conventional conduction and calorimetric techniques.

Shalaby and Zoughi [55] investigated the effect of w/c ratio on the reflection coefficient $|\Gamma|$ of cement and mortar specimens. It was suggested that these types of antenna could be permanently embedded within a cement structure, such that continuous monitoring could be achieved - so called intelligent monitoring of concrete structures. The inner conductor must be placed within the test material, if necessary, by drilling a hole if the cement paste is hardened, so it cannot be considered a non-destructive testing technique. Using these antennas, they derived a correlation between the reflection coefficient and the compressive strength of cement specimens, although the number of specimens tested was limited. They also undertook a comparative theoretical analysis of the response of the reflection coefficient $|\Gamma|$ (as a function of applied frequency) for varying $\mathrm{w} / \mathrm{c}$ ratios, using actual measured dielectric properties of cement specimens. They found that the sensitivity of the $|\Gamma|$ to $\mathrm{w} / \mathrm{c}$ ratio increased when lower frequencies were used. This was attributed to the increased penetration of the applied field into the material associated with longer wavelengths. While this may be true to a degree, at lower frequencies ionic loss mechanisms become more predominant, as these would dominate in the ionic pore solution. The authors did recognise however that the derived relationships were empirical and would be affected further by chemical additives and aggregate inclusions.

Work was conducted in a similar vein by Bois et al [56]. By measuring the microwave reflection coefficient, $|\Gamma|$ as a function of time, mixture specific empirical relationships were derived. It was found the by measuring the derivative product $(\delta|\Gamma| / \delta t)$, the w/c ratio could be monitored at both early (first few days) and late stage curing (about 12 days), although the sensitivity is higher at early ages because the measured gradient was larger at this time. Cure-state monitoring was defined by the 
change in reflection properties, and considered to be largely complete when this change tended to zero. The work illustrated the potential of the technique, although to further develop it, the authors identified the need to define surface effects, the effects of absorbent aggregates, and investigate the depth of microwave sensing into the specimens. It is suggested though that many more variables would affect the measured reflection coefficient, then the three defined by the authors. For example, what about cement and aggregate type, aggregate content and fine to coarse aggregate ratios and the effects of admixtures?

A number of researchers have used microwave based techniques to investigate hydration processes, without directly attempting to develop a stand-alone diagnostic tool. Zhang et al [57] looked at the hydration of slag cements by measuring electrical conductivity $(\sigma)$ and dielectric constant $(\varepsilon)$ using a reflection/ transmission technique by placing the test material in a section of waveguide. It was found that the greater the fraction of slag in the cement blend, the higher the dielectric constant and conductivity. In a later paper [58], the same authors reported the investigation of the early hydration of OPC-HAC (High Alumina Cement) using microwave and calorimetry methods. It was found that the microwave method was more sensitive to the cement hydration. Changes in measured values of $\varepsilon$ ' and $\sigma$ were observed during cement hydration, that were not detected in the measured rate of heat evolution. This is quite interesting, as it suggests that a NDT\&E system is more sensitive to changes in material composition than an established technique. This should be seen a real driver to develop this work further.

By measuring the dielectric properties of early-age concrete, van Beek and Hilhorst [59] were able to evaluate their strength development, based on conductivity measurements and the fact that the more connected the pore structure is, the higher the measured conductivity. They were then able to correlate the measured conductivity of the concrete specimens with their strength development. This is interesting work, as it infers that a remote sensing technique could give microstructural information on the material under test. However, Pavlík et al. [48] described some disadvantages of the methods discussed previously. Reflection or reflection-transmission techniques require the samples to be placed in a resonant cavity or waveguide. As such, they are only suitable for laboratory analysis of 
relatively small samples. The open ended coaxial probe method could be used in situ, but if the material is still in a thixotropic or plastic state, problems could arise from poor contact of the probe to the measurement surface of the sample. Transmission methods can be used, but are limited by the thickness of the material, as the received microwave energy would decrease with increasing thickness leading to measurement errors.

A microwave impulse technique had been shown by Maierhofer and Wöstmann [60] to overcome some of these disadvantages by measuring the water content of a range of building materials to what was stated to be as a good degree of accuracy. The results of the testing showed an almost linear increase in permittivity with increasing water content. This relationship was also found for the loss factor, whilst the pore volume and the distribution of the moisture within those pores accounted for the different slopes of the line for the various materials tested. For a given building material, immersion in the salt solutions did not have a significant effect on the permittivity $\left(\varepsilon^{\prime}\right)$, but the values of the loss $\left(\varepsilon^{\prime \prime}\right)$ showed slightly higher values with increasing salt concentrations. These results are in accordance with those found by Hasted and Shah [61], who also found that the dissolved ionic conductivity did not affect the complex dielectric constant. This could well be due to the discrete nature of the void distribution within the microstructure, as this may limit percolation effects through the material, reducing the contribution to the permittivity by the conductance of the salt phases present. This work is interesting and relevant to the study of chloride induced deterioration mechanisms. So is certainly relevant to durability issue in the field, particularly corrosion of imbedded reinforcement bars.

Following on from the work of Maierhofer and Wöstmann, [60], Pavlík et al. [62] designed a pulsed radar microwave system for monitoring the moisture content (free water) of early age cements that they envisioned could be used in both the laboratory and on site. Changes in free water were then correlated to results of mechanical tests. They measured at early ages (ca. 3 hours after mixing), a slight increase in water content. This anomaly was attributed to an inaccuracy in the calculated value of the permittivity (from which the moisture content is derived), possibly caused by changes in the dielectric properties of the hydration products. A similar problem was also observed by Kuráž et al., [63] and discussed by Pavlík et al [62], but in this case was attributed to temperature changes in the 
cement paste resulting from the heats of hydration. In general, they found that the determined free water contents were in good agreement with all the mechanical tests. This work does however highlight the limitations of basing assumed performance criteria on reductions in moisture content alone. Given the highly complex nature of cementitious systems, this approach may not be wholly appropriate, but shouldn't be precluded from further investigation.

A further paper by Bois et al [64], showed reflection coefficients $|\Gamma|$, of laboratory prepared concrete specimens, could be correlated with coarse aggregate/cement $(\mathrm{ca} / \mathrm{c})$ ratio and $\mathrm{w} / \mathrm{c}$ ratio. These parameters could then be used in conjunction with look-up tables to determine compressive strengths of a given concrete specimen. Peer et al [65] also investigated the change in microwave reflection properties as a function of $\mathrm{w} / \mathrm{c}$ ratio and curing age for a number of cement. It was suggested that measured changes were related to the movement of free moisture within the specimens, which was more than likely due to evaporation from the surface. They also inferred that the change in reflection coefficient was indicative of mechanical strength development within the specimens, but this was not reported in the work.

Peer et al [65] then developed an electromagnetic model for the determination of water movement within hardened cement paste exposed to wetting and drying cycles. Initial results were poor, as only movement of water through evaporation at the surface was considered. After adapting the model to account for movement of water towards the centre of the specimen, the results were much improved. From the simulated values, the water content distribution as a function of distance from the surface into the centre of the specimen was calculated at various intervals during the wetting/drying cycle. The work is certainly a step in the right direction, as it is largely independent of sample composition. The workers indicated that it could be developed to monitor the ingress of deleterious ions such as chloride and sulphate ions and gasses like carbon dioxide. Indeed in another paper, [66] they subjected similar mortar cubes to wetting/drying cycles using a sodium chloride solution. Using their dielectric model, in which a cement cube is resolved into single layers, they modelled the ingress of the sodium chloride solution into the specimen and its subsequent migration both towards the centre of the specimen by capillary draw and to its surface by evaporation. Overall the model was in good agreement with the measured value of both the magnitude and phase of the reflection coefficient. 
Pore solution distribution functions were derived that accounted for evaporation, increasing ionic concentration, for formation of solid products, as well as movement towards both the centre and surface of the cement cube. This type of work is important because it moves away from characterising material properties by deriving empirical relationships. It's difficult to envisage such an approach realising a commercial system because of its inherent lack of versatility at this stage of development. This is the reason the work of Nadakuduti et al., [67] is considered promising. Near-field microwave inspection techniques were used by to empirically model crack detection and characterise their size in cement mortars. In reinforced structures, it is the reinforcing bars that generally fail before the hardened cement. However the size and location of cracks in the concrete are indicative of the tensile strain in the steel rebar, as cracks could be indicative to damage to the reinforcement, irrespective of concrete composition. So developing a commercial system may not necessarily rely on deriving empirical relationships, with their fundamental limitations, like much of the work reviewed.

An attempt was made by Arunachalam et al. [68] to image re-bar in slabs of concrete used for bridge decks. Resolution in the images was poor and is common problem with later work too [69]. In addition problems arise when trying to image concrete that is very wet or has surface water due to attenuation of the applied signal [70]. Non-invasive techniques to probe the structure of concrete, particularly for detecting the presence of steel reinforcement would be very valuable to the construction industry.

Jamil et al., [71] recently investigated the dielectric properties of concrete. The effect of frequency; curing time; w/c ratio; compressive strength; moisture content and the presence of steel fiber were considered. The results showed good correlations between the compressive strength and both the permittivity and loss factor, although only three data points were reported. Bois et al [72] had previously undertaken similar testing and found lower frequencies $(3 \mathrm{GHz})$ to be most effective when measuring the reflection coefficient also consistent with the earlier work of Shalaby and Zoughi, [73]. In the earlier work by related authors, Al-Mattarneh, [74] undertook similar vein by looking at various material properties on the magnitude of the reflection coefficient. The reflection coefficient decreased linearly with $w / c$ ratio and increased with compressive strength. This was attributed to the reduction in 
free water content and pore volume reducing the movement of ionic solution within the concrete matrix.

Donnell et al., [75] used a microwave detection method for differentiating between mortar specimens containing alkali-silica reactive (ASR) aggregates and those without. The action of ASR is of serious concern world-wide, as its formation leads to significant losses in material performance and durability, and is caused by the expansive formation of ASR gel and the associated micro-cracking within the cementitious matrix. The results showed that the ASR reactive and non-reactive specimens could be differentiated by comparison of the transmission coefficient $\left|S_{21}\right|$. This was associated with increased water up-take and the formation of the ASR gel and was supported by the recorded $\% \Delta$ mass of the two specimen sets. Despite these specimens absorbing more water from the humid curing environment, the signal attenuation was less because it was continually bound by formation of the ASR gel. The work demonstrated a novel method for ASR characterisation and the study of the mechanisms of its formation. Further work could relate these properties to variations in gel volume, composition and ultimately damage to the microstructure in susceptible materials.

\subsubsection{Summary}

The use of microwave energy for cure-state monitoring has been demonstrated to be a useful complimentary technique to more conventional conduction and calorimetric analysis, but is essentially measuring the change and distribution of free water through the cement matrix, from which empirical relationships to other properties are derived. The change in dielectric properties and reflection coefficient of cement in the early stages of hydration has been correlated to structural changes in the system, as a result of the hydration process. This is interesting work and possibly the full potential of this type of analysis yet to be realised.

Other workers have used the application of microwave energy to image reinforcement bars in concrete slabs. While the image resolution in this case could be improved, again this relatively early stage work certainly holds promise and is continuing to be an active area of research. 


\subsection{End-of-Life Processing}

\subsubsection{Recycling of Construction and Demolition Wastes}

There are clear incentives to reduce virgin aggregate use and maximise the recycling of Construction and Demolition Wastes (CDW) which constitute a significant portion of municipal solid waste production, with most of it currently landfilled. Within the EU in 1999, 450 million tonnes are generated each year which constitutes roughly $25 \%$ of the total and is its single largest waste stream. Approximately $55 \%$ is currently recycled [76]. In most cases recycled aggregate can be used to make new concrete without having to use virgin aggregate. Concrete can also be recycled when it has outlived its usefulness and converted back into cement clinkers through careful processing.

Construction and demolition waste accounted for $32 \%$ of total waste in the UK as of 2004 [76]. In $200531 \%(28,000,000$ tonnes) of this waste was still sent to landfill. Concrete makes up $15 \%$ of this waste, so recycling in this area could cut landfill costs dramatically [77]. Recycling of concrete also has the benefits of contributing to UK and EU landfill diversion targets, as well as producing a useful commercial product.

Recycled concrete aggregates (RCAs) are produced by reducing the size of concrete demolition waste through crushing and screening processes. Annual UK arising's of 44 million tonnes were produced in 2008 [76]. Following processing, the material comprises of natural aggregates embedded within a matrix of hardened mortar. The presence of this mortar lowers the quality of the RCA, as it reduces the density, has higher water absorption; and lower Los Angeles abrasion resistance compared to natural aggregates [78]. The presence of the mortar limits the amount of RCA that can be incorporated into fresh concrete, as its performance and durability has been found to be proportional to its RCA content. A number of RCA beneficiation methods can be used to lower the 
mortar content of RCA using mechanical and thermal processes, but their net benefits are considered too low because of their high cost or inadequate increases in the quality of the RCA produced.

Current practises involve the breaking, crushing and screening of concrete. Reinforcing bars are removed using magnetic separation techniques, and the crushed material can then be used in a variety of applications, most commonly as foundation material in road construction [79]. The use of recycled concrete in this situation also reduces the demand for primary aggregates, reducing the environmental impacts associated with this practice.

Microwave systems could be used in the demolition process, both in the breaking phase, or as a pretreatment phase in the crushing of the material. Weakening is thought to occur either as a result of thermal stresses due to inhomogeneous heating, or as a result of stresses arising from pore water pressure [80].

The use of microwaves to perform concrete breaking first appeared in literature in 1968 in the form of an experimental study [81] which was able to crack a 5ft square, 9" thick slab of concrete after treatment for two 3 minute periods. Reinforcing bars have been shown to have little influence on the treatment technique in early trials conducted at the tested ISM frequencies of $2.45 \mathrm{GHz}, 10.6 \mathrm{GHz}$ and 18.0GHz. Probably because the reinforcement was embedded further into the concrete than penetration depth of the applied energy. Excavation rates of $1.1 \mathrm{~cm}^{3} / \mathrm{s}$ were achieved at $2.45 \mathrm{GHz}$ and power of $5.2 \mathrm{~kW}$ and $2.1 \mathrm{~cm}^{3} / \mathrm{s}$ at a frequency of $10.6 \mathrm{GHz}$ and power of $3.6 \mathrm{~kW}$. This study showed that higher frequencies produced better results, although the availability of $18 \mathrm{GHz}$ systems and their limited power prevented their utilisation [82]. Excavation depths of up to $2.5 \mathrm{~cm}$ have been reported, however no power information or frequencies were specified in these studies [83]. These excavation rates were slower than those of mechanical methods, but the process has the potential to be optimised to provide a viable alternative. 
Microwave demolition systems have only been demonstrated at laboratory scale. The systems are designed to crack throughout a concrete structure. These breaking systems have the advantage of potentially being far quieter than current mechanical methods, which are often problematic in densely populated areas. Akbarnezhad et al., [84] reported on the microwave-assisted beneficiation of recycled concrete aggregates (RCA's). He believed the process consisted of two parts. Firstly, the microwave heating generates differential thermal stresses in the material termed adhering mortar (AM), which they believed to be particularly prominent at the interface of the AM and the embedded natural aggregates (ENA). They also asserted that as the interfacial transition zone normally has a higher porosity and water content than the bulk mortar, this was said to further aid delamination under microwave heating. Secondly, additional microwave heating were thought to break up the mortar fragments further so they could be separated through sieving.

The workers compared the microwave process to a number of more conventional approaches: thermal; mechanical; thermal-mechanical beneficiation; and two experimental (or unconventional) processes: acid soaking; and chemical-mechanical beneficiation. The experimental trials were undertaken using laboratory cast, concrete specimens made from Type I Portland cement, incorporating granite aggregates and natural sand. These were crushed after curing for 40 days to produce the RCA sample. A pilot scale microwave system was used, consisting of a $10 \mathrm{~kW}$ generator, waveguide components, autotuner, and a directional coupler to measure the forward and reflected power. Although it was not explicitly stated, it is assumed that the frequency of the applied radiation was $2.45 \mathrm{GHz}$, consistent with the system the authors used in their complimentary modelling studies. They found that microwave heating alone for 1 minute liberated more mortar from the bonded aggregates than any of the conventional processes. The liberation effect was greater for RCA that had been prior soaked in water for 24 hours, although this appears to be at odds with their assertion that differential thermal stresses account for the fragmentation. The authors of this paper believe that whilst thermal stress cannot be eliminated as a cause of breakage within the concrete, it is likelier that pore water pressure is the main contributor to the weakening effect. By combining the microwave process with a mechanical rubbing stage, additional removal of weakened mortar was achieved in addition to well as the break-up of the mortar fragments for sieving. Almost $85 \%$ of the mortar could be removed from the RCA, rendering its properties approaching those of natural aggregates. Comparing the process to thermal beneficiation, heating the RCA to a temperature of $500^{\circ} \mathrm{C}$ achieved 
only a $13 \%$ reduction in mortar content, whereas the microwave process achieved a $32 \%$ and $49 \%$ reduction (dry and soaked aggregates respectively) at a temperature of only $150^{\circ} \mathrm{C}$ (and for a much shorter time - $1 \mathrm{~min}$, compared to $120 \mathrm{~min}$ for conventional heating), inferring that the microwave process is more efficient based on lower energy consumption of the system. This also reinforces the likelihood that thermal stress does not play a significant part in the weakening process.

By using single particle testing, Lippiatt and Bourgeois [85] investigated the potential of a combined microwave and physical comminution process for recycling concrete aggregate. This single particle approach was used so that the changes in material properties and energy consumption could be evaluated at each stage of the treatment process. Cubes were exposed to microwave energy using a single-mode applicator being fed from a $2 \mathrm{~kW}$ generator at $2.45 \mathrm{GHz}$ for 10,30 , or $50 \mathrm{~s}$, or left untreated as controls. Comminution properties of the irradiated specimens were investigated using a Hopkinson bar, allowing the total absorbed energy by a particle during impact testing to be measured. These tests showed significant embrittlement of the particles proportional to microwave exposure time, which again provides supporting evidence for a thermal degradation weakening mechanism. Microwave treatment increased the proportion of smaller fragments. This effect can be correlated to the microwave treatment time, and suggests progressive damage to the cementitious microstructure with exposure, which appears to be consistent with a thermal decomposition of the mortar as opposed to the development of thermal stress. Average strengths of the untreated particles were 4.3MPa compared to $0.6 \mathrm{MPa}$ for those treated for $50 \mathrm{~s}$. The results showed that microwave treatment yielded significant increases in material embrittlement and subsequent fracture, as well as reductions in comminution energy and mortar liberation.

\subsubsection{Radionuclide Decontamination of Concrete Structures}

There are clear parallels in the field of radionuclide decontamination with that described in the previous section whereby microwaves are used to target the inherent moisture in the structure to 
promote decomposition of the mortar and fracture either through thermal stress or pore pressure mechanisms although the objectives here are somewhat different. Concrete is a common material used extensively in nuclear engineering for shielding, for nuclear reactor construction, the buildings around the reactors, for hot cells, and waste processing plants. Many of the concrete structures used in nuclear facilities have residual radioactive contamination [86]. For example, at Oak Ridge National Laboratory (ORNL) alone, there are 50,000 tonnes of concrete block, and approximately 2 million $\mathrm{m}^{2}$ of concrete surfaces that have been highly contaminated. The costs of decommissioning nuclear sites and the associated management of the arising low level radioactive waste (LLW) are extremely high. Any reduction in the amount of this waste generated during the decontamination of concrete structures would realise significant cost savings and serve as a driver for the development of such technology. Often, the radionuclide material is only contained in the concrete surface layer and typically comprises: strontium; caesium; cobalt; and uranium [87]. In most cases, only the outer surface of the concrete, to a depth of less than a couple of centimetres, is radioactively contaminated. As regulation of nuclear waste management becomes increasingly restrictive, it is expected that only contaminated concrete surfaces or layers will be treated as radioactive waste, while the main bulk of the concrete treated as a conventional waste stream. Presently, mechanical techniques are used worldwide to separate contaminated concrete surfaces and layers from the bulk concrete. Mechanical techniques have a number of shortcomings. Impact breaking machines generate large amounts of dust, and these machines must be operated subject to wet conditions to suppress dust generation, forcing soluble contamination deeper into the concrete. In addition, high-pressure water sprayers produce huge volumes of secondary contaminated water, and some means for recycling the waste water are needed. Microwave technology has several advantages over conventional mechanical methods, such as minimising the generation of secondary wastes (water and dust), reducing the cost of system maintenance, and lessening radioactive exposure to the worker during operation $[18,84$, 88-90].

As described previously, the use of microwaves to perform concrete breaking first appeared in the literature in 1968 in the form of an experimental study undertaken by Watson and Okress [99]. This initial research encouraged much interest in the area. The use of microwaves for concrete breaking 
showed promise, so other researchers began to explore the potential of the technique for scabbling concrete surface layers with the aim of decontaminating radionuclide concrete surface layers.

White et al., [94] developed a microwave heating process for radionucleotide decontamination of concrete consisting of a fixed microwave generator, waveguide transmission system, applicator and vacuum system for particulate removal. The effect of frequency and power was characterised on the depth and efficiency of concrete removal. Both static and mobile tests were conducted and in all cases material was blasted from the surface of the concrete. During a static test a $2.3 \mathrm{~cm}^{2}$ applicator running off the $10.6 \mathrm{GHz}$ generator created a $2.6 \mathrm{~cm}^{3}$ crater of $1.7 \mathrm{~mm}$ depth at $4.8 \mathrm{~kW}$ in $15 \mathrm{~s}$. Tests were also conducted as the concrete slab was moved under the applicator at a rate of $5 \mathrm{~mm} / \mathrm{s}$. Trenches were cut into the slabs using microwave energy at both frequencies. Based on the amount of material removed, again the system operating at $10.6 \mathrm{GHz}$ was the most efficient compared to the 2.45GHz system.

Based on these findings and the availability of $30 \mathrm{~kW}$ generators at $2.45 \mathrm{GHz}$ it is feasible that rates upwards of $60 \mathrm{~m}^{2} /$ hour are possible which suggests that this technology has clear potential and industrial applicability.

The study of heat transfer in cement-based materials is relatively well developed, given that it has found application in the behaviour of such materials in the fire resistance of buildings and nuclear reactor safety [90-92]. Bažant and Zi., [90] conducted a mathematical analysis of microwave heating and spalling of concrete; and the application of this to not only thermal deformation and surface layer restraint, but moisture transfer, pore pressure overall deformation of the structure. The results of their analysis concluded that the spalling of the concrete surface is not primarily caused by increases in pore pressure from vaporisation of free water.

A paper by Ong and Akbarnezhad [93] used a finite element method to model the thermal stresses in concrete subject to microwave heating. They also determined that the main cause of concrete surface 
delamination was the development of high compressive stresses. These resulted from localised temperature gradients causing non-uniform thermal expansion, as opposed to pore pressures, which supports the work of Bažant and Zi., [94]. The effect was greatest when the free water content of the concrete and the frequency of the applied microwave energy are high. However, the power specified by the model was between 0.5 and $3 \mathrm{MW}$, and no such generator exists at the frequencies chosen by the workers and hence the model cannot be validated. Furthermore, no equivalent model was derived for the pore water pressure system at the same power.

Melcher et al., [95] undertook modelling and experimental tests to investigate the microwave-assisted ablation of contaminated concrete surfaces. They found that at long irradiation times $(>180 \mathrm{~s})$ and low powers ( 1 to $4 \mathrm{~kW}$ ) the specimen melted while short irradiation times ( 5 to $15 \mathrm{~s}$ ) and $>6.5 \mathrm{~kW}$, surface ablation was observed. For water-saturated concrete, this occurred faster than in the dry material and the volume of spalled concrete was also larger, which could suggest a pore water mechanism rather than a thermal stress mechanism is dominant.

\subsection{Microwave based Drilling and Cutting}

Various techniques exist for the drilling and cutting of concrete. These include mechanical drills, lasers, plasma jets, water jets and ultrasonic devices [96-98].

As previously mentioned, mechanical drilling processes are problematic due to the noise, vibrations and dust created. Microwave drilling techniques have the potential to drill silently, and with no dust creation. This leaves good potential for the development of a drilling system, however the accuracy of the technique is significantly lower than that of laser based drills, and so would not be considered for high accuracy drilling.

Jerby and Dikhtiar [96] reported the development of such a device. This consisted of a coaxial waveguide ended with a monopole antenna. This transmits the microwave energy to the concrete 
surface. This centre electrode is movable, so it can be pushed downwards as drilling progresses. The microwave energy is delivered at $2.45 \mathrm{GHz}$ at $1 \mathrm{~kW}$. The electrode is made from tungsten, which can withstand temperatures up to $1500^{\circ} \mathrm{C}$. For higher temperatures, it can be covered with an alumina tube of silicon-carbide tip. The remaining coaxial structure is cooled using pressurised air. When the drill is operated, the microwave energy is concentrated in a hotspot at the end of the drill bit, the high temperatures generated soften and melt the concrete. Laboratory testing has indicated holes of $2 \mathrm{~mm}$ diameter and $2 \mathrm{~cm}$ depth can be drilled within 1 minute with comparable accuracy to mechanical drilling. The material is either compressed against the wall of the hole, or converted to a glass solidified around it. This is dependent on material properties and exposure time. It is suggested that only materials with loss tangents greater than 0.003 and thermal conductivities less than $10 \mathrm{~W} / \mathrm{mK}$ are suitable for this form of drilling.

\section{Discussion}

Microwave processing has been used successfully for the manufacture of cement at laboratory scale. Reductions in both the sintering temperature and processing time have been demonstrated. Only Quéméneur et al [19] was able to produce cement clinker with microwave heating alone, using a relatively high powered single-mode cavity in which relatively uniform high electric field concentrations can be achieved. While for others, this could only be achieved using a combination of conduction heating prior to application of the microwave field, with this heating being produced in a domestic type microwave cavity. It is suggested that these trials were of limited success and the potential advantages of microwave based systems over conventional firing processes do not warrant further research, even at laboratory scale except for those wishing to pursue purely academic study. With respect to the development of pilot-scale processing system, it is recommended that no further work be undertaken in this area. However, specifically considering these studies alone, the use of more focussed applicator of modern design, could be more effective, and do away with the combined heating approach and maybe an interesting comparative study. No work has been undertaken on how the changing composition of the clinker, that occurs during microwave heating, feeds back into 
the coupling mechanisms (and hence heating characteristics) of the material. Furthermore, investigation of the bulk heating characteristics of clinker raw meal using high power modern unimodal microwave systems would be worthwhile, in particular uniformity of heating; a fundamental assessment of the net energy balance; and homogenisation of the final clinker product. But the fundamental issue lies with the poor microwave absorbing capacities of the clinker raw meal components. One of the major difficulties is that quartz (which makes up a large proportion of cement raw meal) is essentially transparent to microwaves at low temperatures. This means that up to $80 \%$ of the solid material cannot be heated at ambient temperatures. This is borne out by the need for some researchers to pre-heat the phases before subjecting them to microwave treatment. To a degree, its loss factor does increase with temperature and so also thereby its heating efficiency. But it was shown in section 3.1 that the use of microwave processing would still consume massive amounts of energy in order to achieve the necessary temperatures for clinkering. The capital cost of a microwave system that could match the processing capacity of a rotary kiln of modern design would be prohibitively high.

Considering the use of microwave process for accelerating the curing of cement based materials, much of the work reported has been on small laboratory scale specimens, which has shown curing times can be reduced without compromising long-term performance. However a significant degree of trial and error is required to optimise the power level and exposure time (specific energy input) as well as the applicator geometry, taking into consideration the variation of aggregate types and $\mathrm{w} / \mathrm{c}$ ratios and their influence on the dielectric properties. This is not a trivial exercise and it is the opinion of the authors that significant investment is required to realise a commercial-scale curing system. The investigation of the so-called non-thermal microwave effect on chemical composition and microstructure and thereby ultimate long-term strength is worthy of further study from an academic standpoint, although it's unlikely to contribute to the realisation of a commerical system. To be commercially valuable, such a system must be scaled to accommodate concrete forms of significantly larger size than those reported in this review. And therein lies that challenge. The depth of penetration of microwave energy may not be sufficient to realise uniform volumetric heating of concrete slabs, structural concrete beams or revetments for example. Radio-frequency energy has a 
much greater penetration depth, although little if any work has been done in this area. Future work should be directed to this end. Focussing on the the use of radio frequency energy is more likely to lead to the development of a commercial-scale system. To establish economic drivers for the development of this technology, the net energy balance should be determined and cost savings of any reduction in curing time be evaluated Once the technique has been proven at scale, however, acceptance of this technology may become more widespread.

The use of Non-Destructive Test and Evaluation (NDT\&E) techniques based on the application of radio and microwave frequencies have been subject to research for several decades. Examination of the literature shows that good correlations between measured parameters such as reflection/transmission coefficient and dielectric property values with fundamental compositional, mechanical and microstructural properties have been derived. The question remains why reliable and robust devices, for the determination of concrete properties have yet to be developed? It is suggested that the reason is that much of the work to date has derived empirical relationships between measured properties and sometimes supported by modelling studies. Much of the work is essentially a measure of the water content in the material, from which empirical relationships of other properties are derived. But these have been undertaken on laboratory specimens whose absolute composition is known. The challenge is the sheer number of material property variables that affect the measured properties and therefore the performance characteristics of the material: cement type; $w / c$ ratio; aggregate type, aggregate size; aggregate to cement ratio; the use of supplementary cementitious materials; other admixtures like superplastizers, set retarders and curing accelerants combined with the effects of site specific environmental curing conditions. The highly complex chemical composition and microstructure of cementitious materials make arbitrary correlations between measured properties and subsequently derived characteristics like compressive strength and $w / c$ ratio highly suspect without first undertaking calibration tests on specimens of equivalent composition and subject to equivalent environmental conditions. To derive all the necessary empirical relationships would simply not be feasible because the amount of work required and its associated time and financial cost would be too great. It is this reason why NDT\&E techniques have not yet progressed from laboratory studies to commercially available systems. Furthermore those techniques relying of 
reflection/transmission measurements require the use of specimens to fit inside a section of waveguide. These could never be developed into a robust on-site tool for use in the construction industry, so it is difficult to see how they would contribute to a commercial system. In the long-term, advances in computer modelling and greater understanding of how chemical and microphysical properties affect bulk properties such as the compressive strength will aid the development of such systems, as it may facilitate the interpretation of the relationship between electromagnetic parameters and material properties without the need for laboratory experiments.

There are clear incentives for facilitating the recycling of construction and demolition wastes. Whilst microwaves offer a viable method of degrading the concrete via the removal of water, it is difficult to envisage microwaves as a widely-applicable tool for the bulk of construction and demolition wastes. Principally due to the large volumes involved, the energy-intensive nature of concrete dehydration, as well as the high capital cost of the equipment. It is not possible however to discount its potential usage for higher value applications where alternative methods are unsuitable, particularly radionuclide decontamination of nuclear sites. It is the view of the authors that given the far-reaching applicability of the technique, the relatively simple engineering involved, the health and safety concerns, and environmental impact of the alternative technologies, microwave-assisted decontamination of concrete warrants further investigation. There is still a question regarding the actual mechanism by which the concrete surface is removed. Some workers state that it is compressive fracture induced by differential thermal stresses caused by the localised heating of the top most surface, compared to the material underneath. Whereas other workers have reported that the scabbling effect is caused by the explosive release of steam, when the pressure exceeds the bonding force in the cement matrix - the steam being generated by the pore solution absorbing the applied microwave energy. Further work to confirm the mechanism of breakage is recommended and would help optimise process. Other challenges to be overcome include the development of a suitable barrier which prevents fragment ingress into the waveguide system and yet allows the unhindered propagation of microwave energy. Pressure transducer technology and/or lasers could indicate whether the required degree of spalling has been achieved. The other main challenge will be to deploy the technology effectively, whereby an effective method of targeting the microwave applicator to the appropriate area is identified. 
Automating the process, in addition to ensuring the effective capture of the radioactive particulate material is necessary. Robotics may well play a part, especially in areas that are difficult to access. Fragment removal tools and dust capture could well be incorporated into an applicator housing design. For a commercialization standpoint, one potential issue that remains to be addressed is the freedom to operate given the number of patent disclosures in the literature.

\subsection{Conclusions}

The development of microwave-based processing technologies for cement and concrete materials has been reviewed. For a particular application, the processing technology is at varying degrees of advancement:

- For the pyro-production of cement clinker, little work advancing the technology has been undertaken in the last 20 years, for good reason. It is unlikely that a commercial scale system can be realized as the energy inputs required are prohibitively high. This is principally due to the fact that the bulk mass of the clinker raw meal components are poor absorbers of microwave energy. Particularly at room temperatures. It is recommended that no further work be directed to this end. However, fundamental property testing and small-scale trials using modern microwave systems would be an interesting study from an academic perspective;

- For accelerated curing, most work has been conducted at laboratory scale, although a smallscale continuous pilot system has been developed. It has been recognised by many workers that the process must be tailored to the material, so as not to affect long-term performance and durability. The potential for scaling-up the technology using microwave energy is limited due to the depth of penetration. This reduces the ability to achieve true volumetric heating, places a limiting factor on the size of the concrete from that can be uniformly treated.

- Conversely, for cure-state monitoring and non-destructive testing, it is still an active area of research. Although the development of a commercially available system has yet to be realised. The majority of the work reported is based on empirical property measurements or 
simply measurements of free-water content. Relating measured properties to fundamental material characteristics reflecting the actual degree of hydration and microstructure development (and thereby macro-physical properties), is still a significant challenge, but achieving this would lead to more versatile systems and possibly wider adoption of their use in industry;

- For end-of-life processing (including radionuclide decontamination) the technology looks very promising, with encouraging results from laboratory trials and small-scale proof-of-concept systems having been developed for decontamination. Further development of these systems would depend on establishing commercial drivers for the technology. This is certainly possible, given increasing pressures on material consumption and resource efficiency, as well as many nuclear sites approaching the end of their service life.

\section{References}

[1] Cement Technology Roadmap, International Energy Agency and World Business Council for Sustainable Development, Paris, France, 2009.

[2] D.E. Clark, W.H. Sutton, Microwave processing of materials, Annual Review of Materials Science, 26 (1996) 299-331.

[3] D.A. Jones, T.P. Lelyveld, S.D. Mavrofidis, S.W. Kingman, N.J. Miles, Microwave heating applications in environmental engineering - a review, Resources, Conservation and Recycling, 34 (2002) 75-90.

[4] A.a. Metaxas, R.J. Meredith, Industrial microwave heating, IET1983.

[5] E.T. Thostenson, T.W. Chou, Microwave processing: fundamentals and applications, Composites Part A: Applied Science and Manufacturing, 30 (1999) 1055-1071.

[6] D.E. Clark, D.C. Folz, J.K. West, Processing materials with microwave energy, Materials Science and Engineering: A, 287 (2000) 153-158.

[7] R. Hutcheon, M. De Jong, F. Adams, A system for rapid measurements of RF and microwave properties up to $1400 \mathrm{C}$. I: Theoretical development of the cavity frequency-shift data analysis equations, Journal of microwave power and electromagnetic energy, 27 (1992) 87-92.

[8] M. Arai, J. Binner, G. Carr, T. Cross, High temperature dielectric property measurements of engineering ceramics, Ceram. Trans., 36 (1993) 483-492.

[9] L. Dongxu, W. Xuequan, A study on the application of vacuum microwave composite dewatering technnique in concrete engineering, Cement and Concrete Research, 24 (1994) 159-164. 
[10] H.C. Rhim, O. Buyukozturk, Electromagnetic properties of concrete at microwave frequency range, ACI Materials Journal, 95 (1998).

[11] P.K. Capros, N.; Mantzos, L.;, Economic Evaluation of Sectoral Emission Reduction Objectives for Climate Change Top-down Analysis of Greenhouse Gas Emission Reduction Possibilities in the EU, National Technical University of Athens, 2001.

[12] L. Parrott, Cement, concrete and sustainability. A report on the progress of the UK cement and concrete industry towards sustainability, British Cement Association, London, (2002).

[13] G.C. Habert, C.; Bouzidi, Y.; Jullien, A.; , Environmental impact of cement

production: Detail of the different processes and cement plant variability evaluation. , Journal of Cleaner Production,, 18 (2010) 478-485.

[14] B. Venkatarama Reddy, K. Jagadish, Embodied energy of common and alternative building materials and technologies, Energy and buildings, 35 (2003) 129-137.

[15] C.S.I. (CSI), Recycling Concrete - Executive Summary, in: H. Klee (Ed.)WBCSD - Washinton, D.C. USA., 2009.

[16] V. Johansen, T. Kouznetsova, Clinker formation and new processes, Proceedings of the 9th International Congress on the Chemistry of Cement, Delhi, India, 1992, pp. 49-79.

[17] C.D. Lawrence, The production of low-energy cements, Lea's chemistry of cement and concrete, (1998) 421-470.

[18] C. Popescu, M. Muntean, J. Sharp, Industrial trial production of low energy belite cement, Cement and concrete Composites, 25 (2003) 689-693.

[19] L. Quemeneur, J. Choisnet, B. Raveau, J. Thiebaut, G. Roussy, Microwave clinkering with a grooved resonant applicator, Journal of the American Ceramic Society, 66 (1983) 855-859.

[20] Y. Fang, D.M. Roy, R. Roy, Microwave clinkering of ordinary and colored portland cements, Cement and Concrete Research, 26 (1996) 41-47.

[21] H. Li, D.K. Agrawal, J. Cheng, M.R. Silsbee, Formation and hydration of C3S prepared by microwave and conventional sintering, Cement and Concrete Research, 29 (1999) 1611-1617.

[22] R. Roy, S. Komarneni, L. Yang, Controlled microwave heating and melting of gels, Journal of the American Ceramic Society, 68 (1985) 392-395.

[23] B.G. Ma, K. Ke, X.L. Wang, X.G. Li, Formation of Tricalcium Silicate Prepared by Electric and Microwave Sintering, Advanced Materials Research, 148 (2011) 1119-1123.

[24] S. Long, J. Dong, C. Yan, Microwave promoted clinkering of sulfoaluminate cement, Cement and Concrete Research, 32 (2002) 1653-1656.

[25] S. Long, C. Yan, J. Dong, Microwave-promoted burning of Portland cement clinker, Cement and Concrete Research, 32 (2002) 17-21.

[26] S. McGill, J. Walkiewicz, G. Smyres, The effects of power level on the microwave heating of selected chemicals and minerals, MRS Proceedings, Cambridge Univ Press, 1988.

[27] B.G. Survey, Mineral Planning Factsheet : Cement, in: D.C. Govenment, Local (Eds.), HMSO, London, 2008.

[28] H.F. Taylor, Cement chemistry, Thomas Telford1997. 
[29] V. Hoenig, H. Hoppe, K. Koring, J. Lemke, ECRA CCS Project - Report about Phase II, TRECRA-106/2009, European Cement Research Academy, Duesseldorf, Germany, 2009.

[30] C.K.Y. Leung, T. Pheeraphan, Microwave curing of Portland cement concrete: experimental results and feasibility for practical applications, Construction and Building Materials, 9 (1995) 67-73. [31] S. Diamond, Delayed ettringite formation—processes and problems, Cement and concrete Composites, 18 (1996) 205-215.

[32] M. Collepardi, A state-of-the-art review on delayed ettringite attack on concrete, Cement and concrete Composites, 25 (2003) 401-407.

[33] T. Erdem, L. Turanli, T. Erdogan, Setting time: An important criterion to determine the length of the delay period before steam curing of concrete, Cement and Concrete Research, 33 (2003) 741 745 .

[34] N. Makul, P. Keangin, P. Rattanadecho, B. Chatveera, D.K. Agrawal, Microwave-assisted heating of cementitious materials: Relative dielectric properties, mechanical property, and experimental and numerical heat transfer characteristics, International Communications in Heat and Mass Transfer, 37 (2010) 1096-1105.

[35] C.L.E. Holm, S. Birch-Rasmussen, Process for curing and drying concrete, Google Patents, 2011.

[36] H.F. Cook, Microwave curing of cementitious material, Google Patents, 1982.

[37] S. Birch-Rasmussen, C.L.E. Holm, Process for curing and drying reinforced concrete, Google Patents, 2009.

[38] W. Xuequan, D. Jianbgo, T. Mingshu, Microwave curing technique in concrete manufacture, Cement and Concrete Research, 17 (1987) 205-210.

[39] R.G. Hutchison, J.T. Chang, H.M. Jennings, M.E. Brodwin, Thermal acceleration of Portland cement mortars with microwave energy, Cement and Concrete Research, 21 (1991) 795-799.

[40] C.K. Leung, T. Pheeraphan, Determination of optimal process for microwave curing of concrete, Cement and Concrete Research, 27 (1997) 463-472.

[41] D. Sohn, D.L. Johnson, Microwave curing effects on the 28-day strength of cementitious materials, Cement and Concrete Research, 29 (1999) 241-247.

[42] I.B. Topçu, M. Uğur Toprak, D. Akdağ, Early estimation of concrete strength with microwave curing method, Mikrodalga kür yöntemi ile beton dayanimin erken belirlenmesi, 19 (2008) 4539-4544. [43] P.J. Tumidajski, B. Gong, D. Baker, Correlation between 28-day and 6-hour compressive strengths, Cement and Concrete Research, 33 (2003) 1491-1493.

[44] A. Korpa, R. Trettin, Very high early strength of ultra-high performance concrete containing nanoscale pozzolans using the microwave heat curing method, Advances in Cement Research, 20 (2008) 175-184.

[45] B. Clark, P. Brown, The formation of calcium sulfoaluminate hydrate compounds: Part I, Cement and Concrete Research, 29 (1999) 1943-1948.

[46] P. Rattanadecho, N. Suwannapum, B. Chatveera, D. Atong, N. Makul, Development of compressive strength of cement paste under accelerated curing by using a continuous microwave thermal processor, Materials Science and Engineering A, 472 (2008) 299-307. 
[47] E. Bescher, M. Sambol, E.K. Rice, J.D. Mackenzie, Determination of water-to-cement ratio in freshly mixed rapid-setting calcium sulfoaluminate concrete using $2.45 \mathrm{GHz}$ microwave radiation, Cement and Concrete Research, 34 (2004) 807-812.

[48] J. Pavlík, V. Tydlitat, R. Černý, T. Klecka, P. Bouška, P. Rovnaníková, Application of a microwave impulse technique to the measurement of free water content in early hydration stages of cement paste, Cement and Concrete Research, 33 (2003) 93-102.

[49] F.H. Wittmann, F. Schlude, Microwave absorption of hardened cement paste, Cement and Concrete Research, 5 (1975) 63-71.

[50] R. Zoughi, Microwave Non-Destructive Testing and Evaluation Principles, Springer2000.

[51] F. Wilson, Concrete, Building Materials Evaluation Handbook, Springer1984, pp. 205-266.

[52] K. Gorur, M. Smit, F. Wittmann, Microwave study of hydrating cement paste at early age, Cement and Concrete Research, 12 (1982) 447-454.

[53] M. Moukwa, M. Brodwin, S. Christo, J. Chang, S. Shah, The influence of the hydration process upon microwave properties of cements, Cement and Concrete Research, 21 (1991) 863-872.

[54] S. Mindess, J.F. Young, D. Darwin, Concrete, 2003.

[55] W. Shalaby, R. Zoughi, Microwave compressive strength estimation of cement paste using monopole probes, Journal of Research in Nondestructive Evaluation, 7 (1995) 101-115.

[56] K. Bois, A. Benally, R. Zoughi, Near-field microwave reflection property analysis of concrete using open-ended rectangular waveguides at S- and X-band, in: S.R. Doctor, C.A. Lebowitz, G.Y. Baaklini (Eds.)San Antonio, TX, 1998, pp. 37-46.

[57] X. Zhang, X. Ding, T. Lim, C. Ong, B. Tan, J. Yang, Microwave study of hydration of slag cement blends in early period, Cement and Concrete Research, 25 (1995) 1086-1094.

[58] X. Zhang, Y. Yang, C.K. Ong, Study of early hydration of OPC-HAC blends by microwave and calorimetry technique, Cement and Concrete Research, 27 (1997) 1419-1428.

[59] A. Van Beek, M. Hilhorst, Dielectric measurements to characterize the microstructural changes of young concrete, HERON-ENGLISH EDITION-, 44 (1999) 3-3.

[60] C. Maierhofer, J. Wöstmann, Investigation of dielectric properties of brick materials as a function of moisture and salt content using a microwave impulse technique at very high frequencies, NDT \& $E$ International, 31 (1998) 259-263.

[61] J. Hasted, M. Shah, Microwave absorption by water in building materials, British Journal of Applied Physics, 15 (1964) 825.

[62] J. Pavlík, V. Tydlitát, R. Černý, T. Klečka, P. Bouška, P. Rovnaníková, Application of a microwave impulse technique to the measurement of free water content in early hydration stages of cement paste, Cement and Concrete Research, 33 (2003) 93-102.

[63] J. Kuráž, V. Matoušek, J. Litoš, The effect of temperature on the measuring of moisture content by a dielectric method, Stavební obzor, 9 (2001) 141-144.

[64] K.J. Bois, A.D. Benally, R. Zoughi, Microwave near-field reflection property analysis of concrete for material content determination, Instrumentation and Measurement, IEEE Transactions on, 49 (2000) 49-55. 
[65] S. Peer, K.E. Kurtis, R. Zoughi, An electromagnetic model for evaluating temporal water content distribution and movement in cyclically soaked mortar, Instrumentation and Measurement, IEEE Transactions on, 53 (2004) 406-415.

[66] S. Peer, K.E. Kurtis, R. Zoughi, Evaluation of microwave reflection properties of cyclically soaked mortar based on a semiempirical electromagnetic model, IEEE Transactions on Instrumentation and Measurement, 54 (2005) 2049-2060.

[67] J. Nadakuduti, R. Zoughi, G. Chen, Empirical modeling of surface crack detection in concrete using an open-ended rectangular waveguide, Golden, CO, 2005, pp. 539-546.

[68] K. Arunachalam, V.R. Melapudi, L. Udpa, S.S. Udpa, Microwave NDT of cement-based materials using far-field reflection coefficients, NDT \&amp; E International, 39 (2006) 585-593.

[69] O. Gunes, D. Lau, C. Tuakta, O. Büyüköztürk, Ductility of FRP-concrete systems: Investigations at different length scales, Construction and Building Materials, 49 (2013) 915-925.

[70] M.T. Ghasr, Y. Le Pape, D.B. Scott, R. Zoughi, Holographical Microwave Imaging of Corroded Steel Bars in Concrete, ACI Materials Journal, 111 (2014).

[71] M. Jamil, M.K. Hassan, H.M.A. Al-Mattarneh, M.F.M. Zain, Concrete dielectric properties investigation using microwave nondestructive techniques, Materials and Structures, 46 (2013) 77-87. [72] K.J. Bois, A. Benally, P.S. Nowak, R. Zoughi, Microwave nondestructive determination of sandto-cement ratio in mortar, Research in Nondestructive Evaluation, 9 (1997) 227-238.

[73] W. Shalaby, R. Zoughi, Microwave compressive strength estimation of cement paste using monopole probes, Research in Nondestructive Evaluation, 7 (1995) 101-115.

[74] H.M.A. Al-Mattarneh, D.K. Ghodgaonkar, W.M.W.A. Majid, Determination of compressive strength of concrete using free-space reflection measurements in the frequency range of $8-12.5 \mathrm{GHz}$, Microwave Conference, 2001. APMC 2001. 2001 Asia-Pacific, 2001, pp. 679-682 vol.672.

[75] K. Donnell, R. Zoughi, K. Kurtis, Demonstration of microwave method for detection of alkali-silica reaction (ASR) gel in cement-based materials, Cement and Concrete Research, 44 (2013) 1-7.

[76] W. Programme, r. Action, AggRegain Material Specifier, pp.

http://aggregain.wrap.org.uk/specifier/materials/recycled_concrete.html.

[77] N. Lawson, I. Douglas, S. Garvin, C. McGrath, D. Manning, J. Vetterlein, Recycling construction and demolition wastes-a UK perspective, Environmental Management and Health, 12 (2001) 146157.

[78] M.S. de Juan, P.A. Gutiérrez, Study on the influence of attached mortar content on the properties of recycled concrete aggregate, Construction and Building Materials, 23 (2009) 872-877.

[79] V.W. Tam, X. Gao, C. Tam, Microstructural analysis of recycled aggregate concrete produced from two-stage mixing approach, Cement and Concrete Research, 35 (2005) 1195-1203.

[80] T.L. White, D.J. Foster, C.T. Wilson, C.R. Schaich, Phase 2 microwave concrete decontamination results, Oak Ridge National Laboratory, Oak Ridge, TN USA, 1995.

[81] A. Watson, Curing of concrete, Microwave power engineering, 2 (1968) 108-118.

[82] C.H. Oh, Hazardous and Radioactive Waste Treatment Technologies Handbook (Handbook Series for Mechanical Engineering), 1 edition ed., CRC Press; 1 edition (14 May 2012)2001. 
[83] H. Yasunaka, M. Shibamoto, T. Sukegawa, T. Yamate, and T. Tanaka. , Microwave Decontaminator for Concrete Surface Decontamination in JPDR, in: G.A. Tarcza (Ed.) Proceedings of the International Decommissioning Symposium, NTIS, Springfield, Virginia, 1987, pp. Pp IV/109— IV/115.

[84] A. Akbarnezhad, K.C.G. Ong, M.H. Zhang, C.T. Tam, T.W.J. Foo, Microwave-assisted beneficiation of recycled concrete aggregates, Construction and Building Materials, 25 (2011) 34693479 .

[85] N. Lippiatt, F. Bourgeois, Investigation of microwave-assisted concrete recycling using singleparticle testing, Minerals Engineering, 31 (2012) 71-81.

[86] T.L.G. White, R.G. Pugh, L.P., Foster, D. Box, W.D., Removal of contaminated concrete surfaces by microwave heating - phase 1 results, Proceeding of the International Symposium on Waste ManagementTucson AZ USA, 1993, pp. 745 - 748.

[87] B.P. Spalding, Volatility and Extractability of Strontium-85, Cesium-134, Cobalt-57, and Uranium after Heating Hardened Portland Cement Paste, Environmental Science \& Technology, 34 (2000) 5051-5058.

[88] C. Anjan K, Chemistry and engineering of the clinkerization process - Incremental advances and lack of breakthroughs, Cement and Concrete Research, 41 (2011) 624-641.

[89] C. Chen, G. Habert, Y. Bouzidi, A. Jullien, Environmental impact of cement production: detail of the different processes and cement plant variability evaluation, Journal of Cleaner Production, 18 (2010) 478-485.

[90] Z.P. Bazant, G. Zi, Decontamination of radionuclides from concrete by microwave heating. I: theory, Journal of engineering mechanics, 129 (2003) 777-784.

[91] D. Gawin, C. Majorana, B. Schrefler, Numerical analysis of hygro-thermal behaviour and damage of concrete at high temperature, Mechanics of Cohesive-frictional Materials, 4 (1999) 37-74.

[92] F. Vodak, R. Černý, J. Drchalova, Š. Hošková, O. Kapičková, O. Michalko, P. Semerak, J. Toman, Thermophysical properties of concrete for nuclear-safety related structures, Cement and Concrete Research, 27 (1997) 415-426.

[93] K. Ong, A. Akbarnezhad, Thermal stresses in microwave heating of concrete, Proc. 31st Our World in Concrete and Structures, (2006) 297-310.

[94] G. Zi, Z.P. Bazant, Decontamination of radionuclides from concrete by microwave heating. II: Computations, Journal of engineering mechanics, 129 (2003) 785-792.

[95] A. Melcher, M. Umminger, T. Kayser, G. Link, M. Haist, H.S. Müller, J. Jelonnek, MicrowaveAssisted Ablation of Contaminated Concrete Surfaces-Modeling, Simulation and Experiments.

[96] E. Jerby, V. Dikhtyar, O. Aktushev, U. Grosglick, The microwave drill, Science, 298 (2002) 587589.

[97] M.K. Kulekci, Processes and apparatus developments in industrial waterjet applications, International Journal of Machine Tools and Manufacture, 42 (2002) 1297-1306.

[98] M. Shamsai, E. Whitlatch, H. Sezen, Economic evaluation of reinforced concrete structures with columns reinforced with prefabricated cage system, Journal of Construction Engineering and Management, 133 (2007) 864-870. 